\title{
LOS LUGARES DE Y PARA LA MEMORIA, UN ABORDAJE DESDE TRES ESTUDIOS DE CASO: Santiago de Chile y Medellín-Colombia
}

\author{
OS LUGARES DE E PARA A MEMÓRIA, UMA ABORDAGEM DESDE \\ TRESS ESTUDOS DE CASO: Santiago de Chile e Medellín-Colômbia
}

\section{LES LIEUX D'ET POUR LA MÉMOIRE, UN APROCHE À PARTIR TROIS ÉTUDES DE CAS: Santiago du Chili et Medellín-Colombie}

\author{
Karen Andrea Vásquez Puerta \\ Estudiante Maestría en Historia y Memoria. Facultad de Humanidades \\ Universidad Nacional de La Plata. Argentina \\ Asistente de proyectos. Corporación Cultural Nuestra Gente \\ Calle 99 No. 50C - 38. Medellín-Colombia \\ E-mail: karenvasquezpuerta@gmail.com
}

\section{Resumen}

El propósito de esta contribución es presentar tres organizaciones de carácter público y privado ubicadas en Santiago de Chile y en la ciudad de Medellín-Colombia como estudios de caso para un análisis comparado entre estas experiencias a partir de la categoría de lugar de memoria. Dicho análisis consta de dos momentos: a) breve contexto geográfico e histórico de los espacios haciendo referencia a las circunstancias particulares en los que surgen cada uno de ellos y las actividades que hoy realizan; b) una lectura de cada caso partiendo de los usos que se le dan hoy al espacio, buscando encontrar los puntos de conexión entre estos y la noción de lugar de memoria. Este abordaje busca responder a la pregunta por la posibilidad de pensar la categoría lugar de memoria ampliada a las experiencias de la memoria cultural que se construye a partir de las relaciones de uso y sentido que los sujetos otorgan al espacio físico.

Palabras clave: Lugar de memoria, pedagogías de la memoria.

\section{Resumo}

O propósito desta contribuição é apresentar três organizações de carácter público e privado localizadas em Santiago de Chile e na cidade de Medellín-Colômbia como estudos de caso para uma análise comparada entre estas experiências a partir da categoria de lugar de memória. A dita análise consta de dois momentos: a) breve contexto geográfico e histórico dos espaços fazendo referência às circunstâncias particulares nos que surgem a cada um deles e as actividades que hoje realizam; b) uma leitura da cada caso partindo dos usos que se lhe dão hoje ao espaço procurando encontrar os pontos de conexão entre estes e a noção de lugar de memória. Esta abordagem procura responder à pergunta pela possibilidade de pensar a categoria lugar de memória ampliada às experiências da memória cultural que se constrói a partir das relações de uso e sentido que os sujeitos outorgam ao espaço físico.

Palavras- chave: lugar de memória, pedagogias da memória 


\section{Résumé}

L'intention de ce texte c'est présenter le travail de trois organisations publiques et privées à Medellín (Colombie) et à Santiago (Chili), servant comme étude de cas afin d'élaborer une analyse comparative entre leurs expériences à partir la catégorie "lieu de la mémoire". Cet étude comporte deux volets: a) la présentation d'un contexte géographique et historique des espaces en remarquant les circonstances particulières où ces organisations ont fait son apparition et les activités qui s'y réalisent actuellement; b) une lecture de chaque cas dont son répère sera l'usage atuel de l'espace, cela dans le but de retrouver les rapports entre ces cas-ci et le concept de lieu de mémoire. Cet aproche essaie de répondre à la demande pour la possibilité de penser à la catégorie de lieu de mémoire liée aux expériences de la mémoire culturelle, construite selon les rélations d'utilisation et de sens données pour les sujets à l'espace.

Mots clefs: lieu de la mémoire, pedagogías de la mémoire

\section{Introducción}

Los estudios sobre el pasado reciente en América Latina tienen como punto de partida acontecimientos tan impactantes como las últimas dictaduras cívico-militares en países del cono sur como Argentina, Chile y Brasil, que se sucedieron en los años 70' y 80 ', en los cuales el proceso de transición a la democracia ha generado entre los investigadores de las ciencias sociales e historiadores un gran interés y una amplia producción académica al respecto.

Algunos de los debates están motivados desde las premisas del Nunca más y Recordar para no repetir, y a partir de esto se han generado iniciativas de reparación a las víctimas y denuncia del terrorismo de Estado a través de variadas herramientas y estrategias como museos, memoriales, designación de fechas conmemorativas dentro de los calendarios nacionales y se le ha otorgado un valor preponderante a la transmisión de la historia del pasado reciente desde la escuela.

Este trabajo tiene como base teórica los análisis de investigadores de las ciencias sociales, la historia y la geografía que han actualizado la noción lugar de memoria de Pierre Nora, y esto se ponen a la luz de tres estudios de caso ubicados geográficamente en ciudades diferentes:

El parque por la Paz Villa Grimaldi en Santiago de Chile, un ex-Centro Clandestino de Detención que operó durante la dictadura de Augusto Pinochet; y en la ciudad de Medellín (Colombia) la Corporación Cultural Nuestra Gente, una ONG de carácter artístico y el Museo Cementerio San Pedro, el más antiguo de la ciudad y que hoy día es reconocido como una de las experiencias culturales más importantes del país y de América Latina. 
La noción lugar de memoria se asocia de manera casi que inmediata con el concepto ampliamente desarrollado por el historiador francés Pierre Nora en el texto que lleva por título Les Lieux du Mémoire escrito entre 1984 y 1992. El autor concibió en un primer momento a los lugares de memoria como una forma de cristalización de la misma; más adelante realizó una actualización de la noción, pasando de ser aquello que cristaliza y refugia a la memoria cuando ella misma se ha perdido, a otorgarle un carácter más amplio que incluye a aquellas unidades significativas en las que convergen elementos simbólicos que se hacen parte del patrimonio memorial.

Desarrollos posteriores han vinculado a los lugares de memoria con los estudios e investigaciones de la memoria política o memorias nacionales de los países que han pasado por gobiernos dictatoriales. En el caso del cono sur de América Latina parece haber cierto consenso respecto a las funcionalidades del lugar de memoria dentro del espacio público: rememorar, conmemorar y denunciar.

Respecto a este asunto es preciso aclarar que la iniciativa de este trabajo parte de la reflexión sobre esta perspectiva del lugar de memoria con unas funcionalidades predeterminadas y de este modo me permito expresar que esta contribución se aleja de esto, para pensar que el lugar de memoria y los sentidos que se tejen al rededor de ellos se construyen en el intercambio entre las narrativas que cada uno construye a partir de las imágenes y recuerdos que tiene sobre el pasado -que se reflejan en diferentes tipos de relatos- y en la experiencia concreta con el lugar específico. Esto es lo que se encuentra tras los memoriales, monumentos y espacios declarados como lugares de memoria, por tal razón considero que no es posible generar una reflexión crítica a las siguientes generaciones o a las personas que no vivieron los acontecimientos a los que aluden los lugares de memoria, si éstos siguen siendo producidos por políticas públicas gubernamentales y la experiencia no se vincula a otros tipos de relatos.

Referirse a los lugares de memoria implica necesariamente preguntarse ¿desde dónde y cómo se abordan? ¿cuáles son los discursos que circulan y los legitiman?, ¿qué impactos alcanzan sobre las personas que los visitan? ¿qué implica dicha materialidad de la memoria? [JELIN, 2002:54].

Si bien los lugares de memoria han contribuido a la recuperación de la memoria social urbana y nacional, se les ha anquilosado dentro del discurso de la memoria política y pareciera que es ese el ámbito que los define y legitima, es decir, son las políticas gubernamentales las que instalan los lugares de memoria, imponiéndose el discurso y la legitimidad del mismo desde arriba hacia abajo. 
Frente a este panorama se ha ampliado la perspectiva de análisis incluyendo a las memorias perfomativas como la posibilidad de hacer uso de otros lenguajes para la construcción de nuevos registros, Schindel lo propone de la siguiente manera: "Si el dolor es un momento previo al lenguaje, a la capacidad de simbolización y objetivación; es tarea de la cultura dar un marco de comprensión simbólica que imagine y reponga el lenguaje que el dolor destruye [...] Nuevos y mejores dispositivos de homenaje resultarían inocuos si no se acompañan de una experiencia sensible y cotidiana del recuerdo. Acaso la memoria, antes que afincarse en espacios memoriales prefijados, viva la decisión de registrar las huellas del pasado en el paisaje urbano...” [2002:32]

Teniendo en cuenta lo anterior, puede considerarse que los lugares de memoria y las memorias performativas son complementarias en la medida en que cuestionan las formas de la representatividad. Hernán González [2010] escribe: "Es que no es posible pensar la representación del horror, problema que se puede traducir como la representación de lo irrepresentable, o la irrepresentación de una representación, sin proponer nociones como alegoría y paradoja."

Lo anterior puede ponerse en diálogo con la propuesta de Aleida Assmannn sobre la memoria funcional, entendiéndola como "...la apropiación y retransmisión a las memorias individuales a través de instituciones de canonización, educación, formación y puesta en escena pública de la cultura.” [2004:24], esto permite la transmisión oral del recuerdo de lo vivido y lo sabido entre generaciones y contribuye a generar procesos de identificación grupal.

En este trabajo se aborda a partir de estos cuestionamientos teóricos y las reflexiones que se generaron después de visitar cada uno de estos lugares: ¿Cómo pensar estos espacios como lugares de memoria?, en el caso de la Villa Grimaldi: ¿toda su carga simbólica está puesta por lo que se vivió allí o por lo que se quiere transmitir en el presente? ¿tienen el horror, el miedo, el dolor una esfera de representatividad?, es decir, ¿existen límites para lo que puede ser representado y las formas para tal propósito? Para los casos de la ciudad de Medellín: ¿Caben estos espacios dentro de la categoría lugar de memoria? ¿Existe una categoría que reúna mejor lo que el lugar es en sí mismo y lo que representa?

\section{Los casos}

\section{Caso 1. La Villa Grimaldi.}


El primer caso está ubicado en Santiago de Chile, que durante los 17 años de la dictadura cívico-militar que vivió el país -bajo la dirección del General Augusto Pinochet- se presentaron un sin número de violaciones sistemáticas a los derechos humanos, a través de secuestros, desapariciones forzadas, detenciones ilegales, exilios, censura. Bajo este gobierno se creó en 1973 la Dirección de Inteligencia Nacional (DINA) que funcionó hasta 1977, sus funciones estaban concentradas en el secuestro, tortura y desaparición de personas; el régimen de terror que impuso la dictadura implicaba a su vez la aplicación de distintas técnicas de tortura sobre los detenidos, las cuales eran llevadas a cabo en espacios conocidos hoy como ex Centros Clandestinos de Detención (CCD).

En Chile se registraron unos 1.132 CCD según informes oficiales, entre estos se encuentra el Parque por la Paz Villa Grimaldi el cual funcionó entre 1973-1977, en 1997 fue recuperado y se mantiene hasta el día de hoy abierto a los visitantes desarrollando diversas actividades académicas y culturales.

En el momento en que funcionaba como CCD era conocido como el Cuartel Terranova a cargo de la DINA, ha sido catalogado como el Centro Clandestino de Detención más grande de Chile ya que gran parte de los detenidos, detenidosdesaparecidos y ejecutados políticos pasaron por la Villa Grimaldi. Algunos de los detenidos pertenecían a partidos de izquierda como el Movimiento de Izquierda Revolucionaria (MIR), del Partido Comunista (PC), del partido Socialista y del Movimiento de Acción Popular Unitaria (MAPU), cada uno de ellos ha erigido un memoria a sus integrantes secuestrados dentro de la Villa.

La Villa Grimaldi estaba dotada de diferentes salas de tortura en las que se encontraban parrillas eléctricas, cuartos de aislamiento -de 1x1 m. de espacio- y una torre de agua, que según testimonios de los detenidos que sobrevivieron, quienes eran llevados a la torre no sobrevivían.

Con el fin de la dictadura todo lo que estaba en el Centro Clandestino fue demolido y hubo un intento de venta ilegal del predio para la construcción de un conjunto habitacional, pero la intervención de los habitantes del sector permitió recuperar el espacio para que se construyera el Parque por la Paz Villa Girmaldi, inaugurado el 24 de marzo de 1997. 


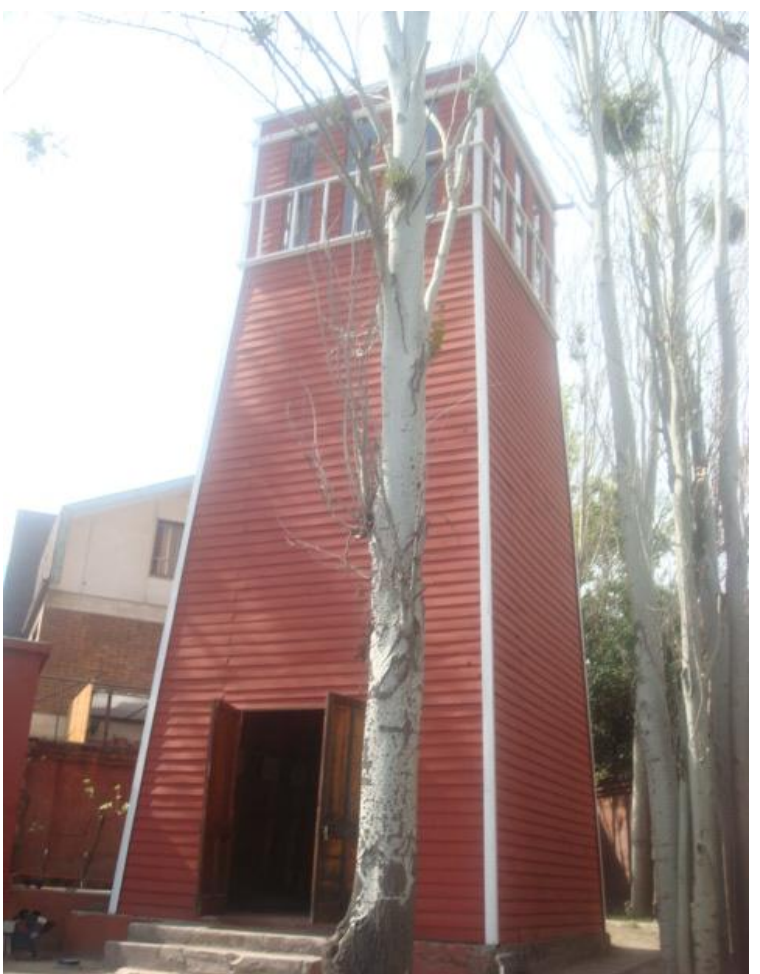

Figura 1 - La propuesta del parque está compuesta por una intervención artística, la reproducción de los espacios de tortura acompañados por los dibujos realizados por un sobreviviente, hay además una maqueta del cuartel, un jardín de rosas en homenaje a las mujeres desaparecidas de la Villa Grimaldi, varias fuentes de agua, el mural con los nombres de los desaparecidos y asesinados, un archivo de testimonios de sobrevivientes y un pequeño museo con fotografías y homenajes a las víctimas por parte de los familiares.

El Parque por la Paz ha sido pensado como un espacio para la demanda de verdad, justicia y reparación, desde la dirección del lugar lo presentan como un sitio de conciencia, donde una de sus actividades principales es la visita guiada dirigida a todo tipo de público, con un objetivo educativo, reflexivo, conmemorativo, informativo y de reparación a las víctimas.

Por otro lado tenemos los casos de la ciudad de Medellín-Colombia, que para una mayor comprensión de su particularidad remito a la situación de conflicto que vivió la ciudad en los años 80', lo que significó un momento atroz caracterizado por una violencia criminal que marcaría el antes y el después de la ciudad. Se iniciará la década con fuertes problemas de desempleo, lo que conllevó a un aumento de los niveles de pobreza y marginalidad, dándose a su vez una nueva ola de desplazamiento que, -a diferencia de la que se dio en los años 50' y 60' específicamente del campo hacia la ciudad - tiene una dimensión urbana, es decir, los habitantes ya instalados en la ciudad 
tuvieron que desplazarse desde otras zonas hacia la periferia del norte.

En estas circunstancias, tanto para los nuevos como para los anteriores moradores, la inclusión en las dinámicas de la ciudad fue limitada, los niveles de pobreza eran altos y el acceso a oportunidades laborales, educativas, de acceso a servicios de salud o bienes culturales no se satisfacían. Sumado a ello, (el desempleo, la pobreza extrema y el desplazamiento) se presentó una agudización del problema del narcotráfico asociado a la emergencia de varias bandas criminales y el aumento considerable de acciones violentas como el sicariato. Ello generó un fuerte estigma sobre la ciudad, especialmente sobre la Zona Nororiental, en la cual se encuentran ubicado los dos casos de estudio de este trabajo.

En palabras de la profesora de Teresa Uribe "La cultura, la socialización de jóvenes y niños, la formación de ciudadanos modernos, la historia, el patrimonio urbano, el medio ambiente y la ética pública fueron dejados a su propia suerte y terminaron por hacer eclosión en la década del ochenta, contribuyendo a crear las condiciones para la precipitación de la crisis" . [1994:13]

Estas y otras situaciones generaron una amplia brecha en los niveles de desigualdad entre los habitantes de la ciudad llevando a una división más marcada y evidente entre el norte y el sur, distanciando a los más favorecidos ("los del sur") de aquellos con menos oportunidades, llegando incluso a considerarse que estar en el centro de la ciudad y dirigirse hacia el norte significaba -para el imaginario colectivouna sentencia de muerte.

Para dar cumplimiento con el propósito de este trabajo, realizaremos una breve contextualización geográfica e histórica que permita una mayor comprensión de la particularidad de estos casos.

Tenemos entonces que la escala territorial de la ciudad de Medellín está organizada en 6 zonas, 16 comunas y 249 barrios oficiales; las zonas están conformadas por comunas y estas corresponden a un conjunto de barrios que se identifican con un nombre y un número.

La zona Nororiental de Medellín -que en el mapa de abajo se identifica con el color verde-, fue habitada casi en un $70 \%$ por asentamientos ilegales durante las décadas del 50' y los 60', está conformada por las comunas 1 Popular, 2 Santa Cruz, 3 Manrique y 4 Aranjuez, el conjunto cuenta en total con 52 barrios que durante las décadas de los 80' y 90' fueron el epicentro de la violencia dentro de la ciudad, manifestada en homicidios, robos a mano armada, disputas por el territorio entre las bandas que se 
encontraban instaladas en los barrios y cuya mayoría se encontraban concentradas en esta zona.

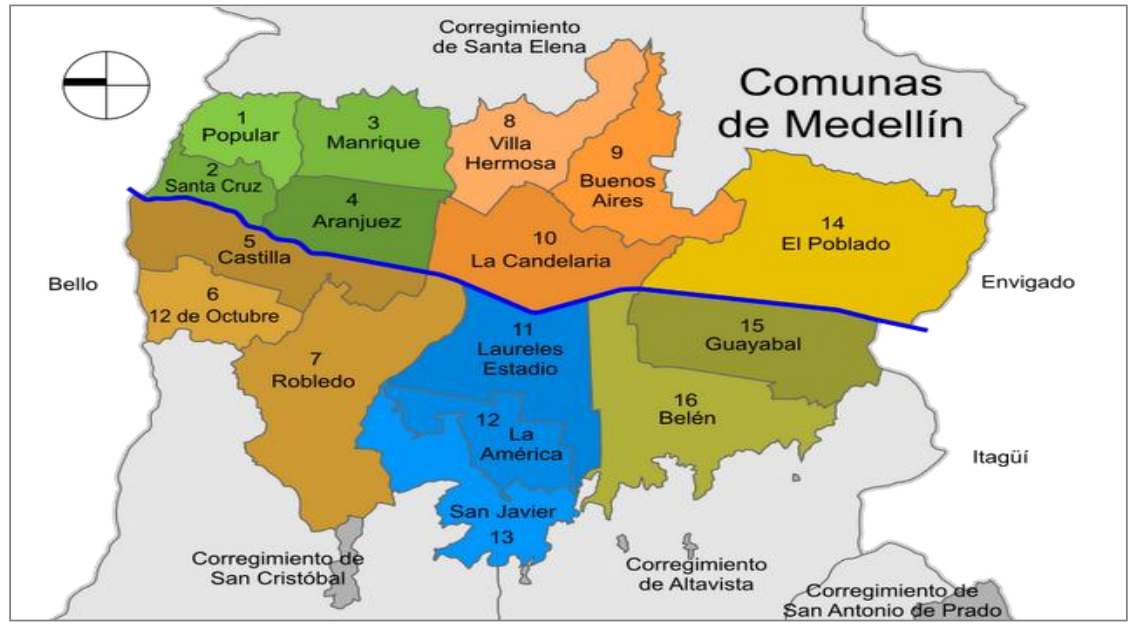

Figura 2 - Mapa de las Zonas y Comunas de Medellín. Fuente: Alejandro Sajor.

El investigador Raúl Ceballos la describe así: “[...] se trata de una de las zonas tradicionalmente más desatendida por el Estado. Asimismo fue una zona fuertemente estigmatizada: por razones políticas debido a que albergó barrios de tradición gaitanista y luego barrios de invasión en cuyas luchas, a veces cruentas, se puso de manifiesto la influencia de los movimientos de izquierda; fue estigmatizada además por ser sede de reconocidos lugares de prostitución, combatidos por la moral pública como epicentros de perdición y por las autoridades como refugio de delincuentes; fue estigmatizada también socialmente porque se la escogió como sitio de reubicación de gentes desalojadas de otros lugares de la ciudad.” . [2009:390]

Fue un periodo entonces en el que los habitantes de la zona se encontraban en una situación de incertidumbre constante, generando además el escenario ideal para la entrada del narcotráfico, ya que para muchos esto significaba una importante fuente de ingresos económicos, reconocimiento y poder que nunca antes habían tenido y consideraban no podían obtener de otra manera.

Se empezó a pensar o a construirse, una cultura de la violencia generada por el narcotráfico, o bien una lógica mafiosa que se vinculó a la vida de la ciudad, esto favoreció el surgimiento de unas nuevas formas de relacionarse entre vecinos y de éstos con el territorio.

Es decir, el barrio como territorio común se convirtió en un campo de batalla que incluía fronteras, que para los moradores eran invisibles pero para quienes se disputaban 
el territorio eran visibles, inviolables y conquistables, el morador pasó de ser vecino a convertirse en amigo o enemigo.

Las disputas por el control del territorio no sólo se daban entre las bandas delincuenciales asociadas al narcotráfico, sino también entre grupos militantes de partidos políticos, cuadros guerrilleros pertenecientes a las Fuerzas Armadas Revolucionarias de Colombia (FARC) o el Ejército de Liberación Nacional (ELN), y los grupos de autodefensas urbanas, conocidos como milicianos.

De esta manera el conflicto se agudizó en dos direcciones, hacia adentro de la zona por los enfrentamientos dados entre los grupos armados ya mencionados, y hacia afuera, ya que la mayoría de las acciones delictivas (robos a bancos, atentados con explosivos contra personas, medios de comunicación o empresas, asesinatos a mano armada, entre otras) se ejecutaban en el centro o en las afueras de la ciudad de Medellín, uno de los motivos por los cuales llegó a ser catalogada en ese momento como la ciudad más violenta del continente.

Como consecuencia de la violencia dada para este momento y paralelo a los conflictos que seguían presentándose, a finales de los años $80^{\prime}$ se dio lugar a la formación y consolidación de procesos de organización juvenil que se crearon en este periodo de tiempo, entre los mismos encontramos grupos de punk y música andina, grupos teatrales y organizaciones cívicas, algunas de ellas se mantienen hasta hoy.

Si bien el fenómeno de la violencia en la ciudad está fuertemente marcado y guiado por el narcotráfico y el conflicto urbano que se dio en la zona, aparecen también otras formas de organización cuyas acciones se dirigen hacia la reconstrucción del tejido social dañado, apuestas por la ciudad que se vinculan desde el arte y la educación como pilares de la transformación de la ciudad y de las vidas de las personas.

La Zona Nororiental, aún recordada y reconocida por la oleada de violencia de los años 80' y 90', con estigmas tan arraigados y legitimados como Pablo Escobar, la producción y el tráfico de drogas y el cartel de Medellín, es el escenario en el que aparecen los casos a exponer, la Corporación Cultural Nuestra Gente y el Museo Cementerio San Pedro.

\section{Caso 2. Corporación Cultural Nuestra Gente}

Dentro de la Zona Nororiental se encuentran concentradas cuatro comunas, el segundo estudio de caso de este trabajo está ubicado geográficamente en la Comuna 2Santa Cruz. Allí surge esta ONG en plena crisis de finales de los ochenta (1987), como 
una iniciativa del grupo juvenil de la parroquia del barrio que consideraban que el barrio debía tener un espacio cultural que hiciera resistencia a través del arte a esta crisis.

La Corporación Cultural Nuestra Gente es una organización social de derecho privado e interés público, sin ánimo de lucro, de carácter cultural y comunitario, con un componente original en teatro, cuyo objetivo principal ha sido brindar un espacio en el cual el arte y la cultura contribuyeran a recuperar el espacio público y la confianza entre los habitantes.

Durante 25 años, Nuestra Gente ha desarrollado procesos permanente de formación y capacitación artística con niñas, niños, jóvenes, adultos y adultos mayores, en áreas como el teatro de calle, sala, títeres, danza, música, literatura, fotografía, video y artes plásticas. También acompaña procesos de planeación del desarrollo sociocultural local y la comunicación comunitaria, posicionándose hoy como una de las organizaciones artísticas comunitaria de base más fortalecida de la ciudad, alcanzando un nivel de credibilidad y confianza dentro de la comunidad y liderando procesos tan importantes como la RED Latinoamericana de Teatro en Comunidad y la Campaña Continental de la Cultura Viva Comunitaria.

Comenzó siendo una biblioteca comunitaria, ahora es un centro cultural muy potente y de alta proyección que con su labor comunitaria ha logrado transformar el imaginario y actualizar el recuerdo que sobre el espacio físico que ocupan hoy -su sedese ha depositado.

La actual sede de Nuestra Gente es el antiguo burdel de la Zona, que antes del proceso de urbanización que se dio en los años 60' y 70' estaba por fuera del perímetro urbano de la ciudad y constituía parte de la zona de tolerancia de Medellín, que abarcaba incluso a otras comunas como la 4-Aranjuez, donde se encuentra ubicado el tercer caso.

El director de la corporación Jorge Blandón ${ }^{1}$ lo relata así:

\begin{abstract}
"El barrio tiene un referente cultural que ha pesado en su historia y en la de sus habitantes, ya que en sus cercanías funcionó hasta bien entrados los años setenta una zona de tolerancia conformada por cantinas y burdeles. Estos elementos representaban un símbolo cultural bien complejo: todos iban de paso, generando así un tejido social del desarraigo, del nomadismo, que impidió durante muchos años producir esa cultura de barrio donde no solamente se duerme sino que se construye vida, historia. Así, los burdeles eran los referentes reales del barrio."
\end{abstract}

1 Entrevista realizada a Jorge Iván Blandón, director Corporación Cultural Nuestra Gente. Febrero 2012. 
"Copinol 2" era el nombre del burdel que es hoy sede de Nuestra Gente, sobre él se han tejido muchas historias y personajes, pero sobre todo hay una carga simbólica muy fuerte entre los habitantes del barrio, pues marcó generaciones enteras como un sitio de paso prohibido para los niños y niñas, las esposas temían que sus esposos visitaran el lugar y las abuelas del barrio eran las costureras de los trajes de las prostitutas.

A finales de la década del 70' tras el asesinato de una de las prostitutas en el salón de baile, dejó de funcionar y la casa quedó abandonada, luego fue dada en venta a una fábrica de colchones que quiebra a finales de los $80^{\prime}$ y la casa permanece vacía hasta 1995.

En este periodo de tiempo la disputa por territorio era muy fuerte en el sector y había restricciones para pasar de un barrio a otro, así que el equipo de jóvenes de Nuestra Gente no tenían una sede fija hasta que compran la casa a través de un crédito.

La casa se adapta a las nuevas necesidades del grupo artístico de la corporación, así las habitaciones del burdel se convierten en la biblioteca, el salón de música, danza y oficinas y el salón de baile en el escenario.

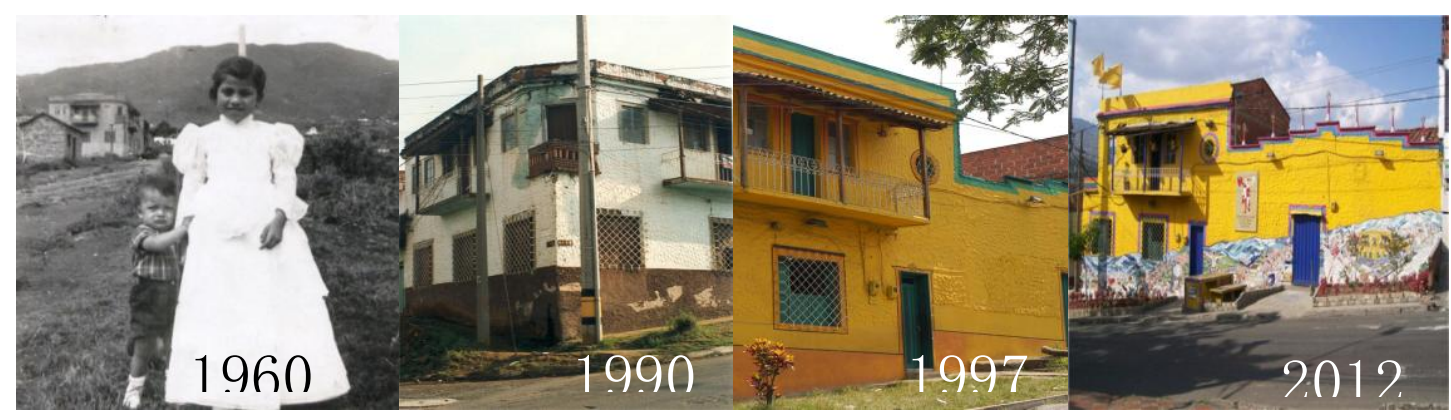

Figura 3 - Transformaciones de la fachada.

Fuente: Archivo Corporación Cultural Nuestra Gente.

El conflicto armado en este sector no se fijó de manera visible en la zona ni en la ciudad, es decir, no hay muestras de destrucción ni se han registrado técnicas de tortura o desaparición, pues la lógica del terror era particular. A pesar de esto si hay indicios evidentes de este conflicto entre los habitantes de la comuna, que se ve reflejada en las nuevas apropiaciones que se hicieron sobre el espacio, algunos barrios donde la intensidad del conflicto era mayor, fueron estigmatizados con más fuerza que otros, y dentro de los mismos barrios se vetaron caminos, calles, se estableció un toque de queda informal y se generó un proceso de identificación hacia los habitantes asociado al lugar de vivienda, donde cruzar de un barrio a otro era en sí mismo un suicidio. Algunas de 
estas prácticas e imaginarios permanecen.

Por tal razón el equipo de Nuestra Gente ha dirigido sus acciones -desde ese momento hasta hoy- a procurar una nueva apropiación del territorio y transformarlo en lugar, buscando que se cargue de un sentido nuevo. Este proceso lleva 25 años, buscando que las prácticas artísticas en y para la calle le den otro sentido al barrio, que los jóvenes que no vivieron este momento de violencia se relacionen de manera diferente con el espacio y con sus vecinos, y que los adultos que fueron jóvenes en ese momento -y sobrevivieron- se reintegren a las dinámicas barriales perdidas en ese momento. La intencionalidad está puesta sobre la idea de que el barrio es el edificio de la memoria y en esta medida es necesario resignificarlo como un espacio para la vida y la vecindad.

Bajo esta premisa desde 1996 se realizan actividades enfocadas desde el arte hacia la recuperación de la memoria colectiva enfocada en la historia del proceso de urbanización de la Comuna, la conformación de los barrios y las dinámicas barriales que tuvieron lugar en los primeros 30 años.

Durante estos años han realizado 3 puestas en escena con los habitantes del barrio que tienen como tema central reconstruir la historia de los barrios como parte del proceso que ha adelantado la comuna 2 de reconstrucción de la historia de poblamiento de los barrios.

\section{Caso 3. Museo Cementerio San Pedro}

El último caso de este abordaje es el Museo Cementerio San Pedro, construido en 1842 y nombrado en 1999 como monumento nacional, es el primer cementerio privado fundado por las familias de clase alta de Medellín, justamente los miembros de la elite comercial, política, económica e intelectual de la época. Para la década de los 80' el cementerio entra en una crisis financiera debido a que las familias asociadas dejaron de hacer uso de los servicios del cementerio por diversas razones -entre las que se incluían el recrudecimiento de la violencia en la ciudad y el desplazamiento de dichas familias a la zona sur de la ciudad que estaba constituida por departamentos- por lo tanto la administración se vio obligada a prestar el servicio funerario a familias de clase media y baja para poder mantenerse en términos financieros.

Es así como el cementerio atraviesa por un momento muy particular y es que pasa de ser el recinto de las familias más adineradas de la ciudad e incluso del país, a ser el receptor de muchos de los muertos del sicariato de Medellín, tanto de los integrantes

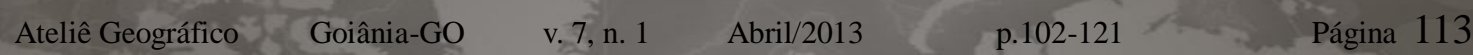


de las bandas como de algunos narcotraficantes de clase media e incluso de las víctimas inocentes del conflicto, muchos de ellos habitantes de barrios cercanos al cementerio.

Con estas nuevas condiciones, el ritual de la muerte dio un giro muy importante ya que pasó de ser un ritual funerario de luto y en silencio acompañado por las familias y allegados, al desplazamiento de una cantidad considerable de habitantes del barrio, amigos, vecinos, familiares que acompañaban el cadáver.

Las personas se desplazaban en buses de la ruta que cubría el barrio, iban al cementerio en sus ropas habituales y siempre acompañaban a su muerto con música en alto volumen, con una grabadora que reproducía sus canciones favoritas. En algunas ocasiones integrantes de la banda contraria llegaban al cementerio a arremeter violentamente contra algún joven que asistía a la despedida de su compañero, o para asesinar a algún familiar, presentándose así un enfrentamiento armado dentro del cementerio, acompañado por el sonido de la salsa o las letras de hip hop que aun sonaba en la grabadora.

La descripción de un periodista anónimo ilustra mejor lo que allí acontece: "El cementerio de San Pedro de Medellín, se ha convertido en un escenario más propio para los asuntos de los vivos que un remanso para el eterno descanso de los muertos. Allí es normal que la gente de serenatas, eleve cometas, tome fotos, beba aguardiente, destape fiambres, levante novia, dispare tiros, meta vicio y pare de contar...Este campo santo es lo más parecido a un barrio."2

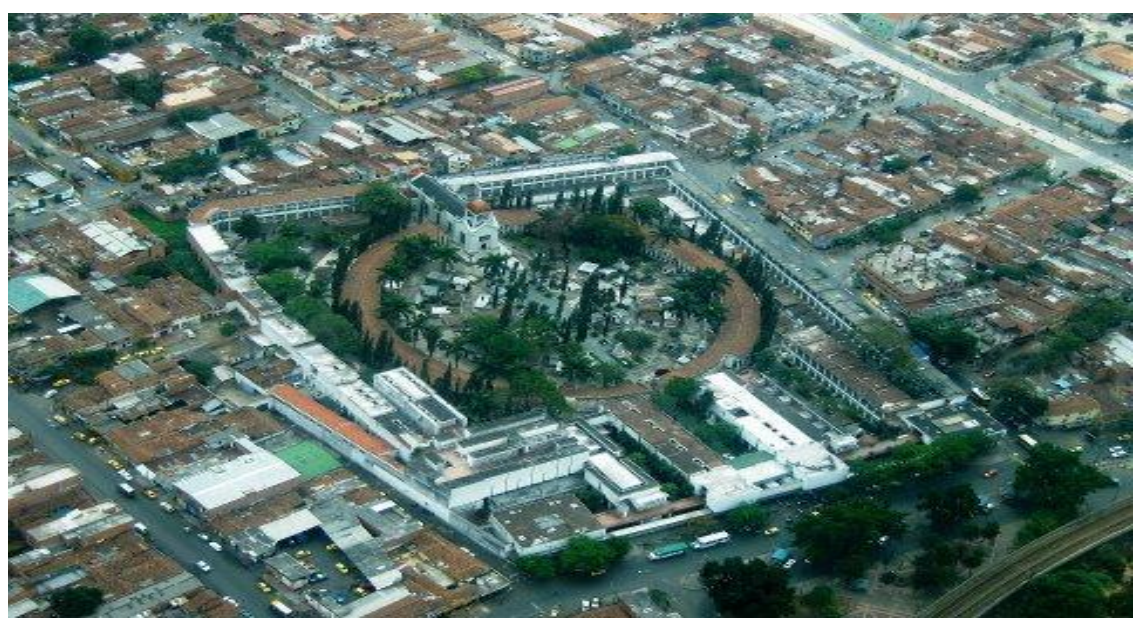

Figura 4 - Vista panorámica del Museo Cementerio. Fuente: Archivo Museo Cementerio San Pedro

2 Extraído de la crónica Cementerio de San Pedro: Un mundo de historias, soledad y animales. En: www.soyperiodista.com 
Este cambio en las relaciones entre los habitantes de la ciudad y el cementerio tuvo su impacto en la administración del mismo, que para 1996 se propuso generar estrategias para recuperarlo como un espacio que podía contribuirle a la ciudad en la reconstrucción del tejido social que estaba tan debilitado tras la guerra del narcotráfico. Se creó un archivo fotográfico compuesto por 2.700 fotografías con las que contaban y a las cuales no se les había hecho registro ni sistematización, ésta y otras actividades permitieron que en 1998 fuera el primer cementerio de América Latina en ser declarado museo, más tarde se integra a la Red Iberoamericana de Museos Patrimoniales de la región y para el año siguiente es nombrado Bien de Interés Cultural de la Nación.

Para el año 2000 el museo cuenta con un equipo de trabajo conformado por historiadores, comunicadores sociales y artistas plásticos, encargados de realizar la programación cultural y académica del cementerio que incluía noches de cuentería, teatro, talleres de duelo con los familiares, actividades recreativas vacacionales, exposiciones, estas actividades buscan vincular a todos los grupos de edad y llegar a la mayoría de los habitantes de la ciudad.

Entre las actividades que se realizan en el museo resalto los talleres Arte Vivo que inician en el año 2006 y se ocupan específicamente de recuperar la memoria patrimonial de la ciudad a través de visitas guiadas al cementerio y recuperar las memorias propias a través de talleres manuales.

En un primer momento tenían un enfoque de acompañamiento en la elaboración del duelo para las familias y poco a poco el equipo académico del museo dio un giro al proyecto y amplió los talleres a toda la comunidad buscando una mayor proyección del cementerio, como un lugar que contenía en sí mismo la historia de la ciudad de Medellín, pero cada uno de sus visitantes tenía también una memoria que podía ser compartida con otros y elaborada a través del arte.

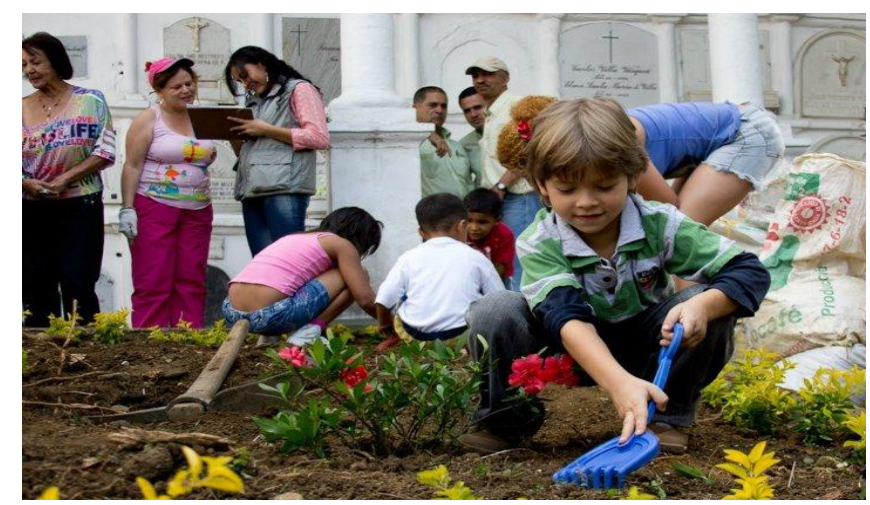

Figura 5 - Taller Arte Vivo.

Fuente: Archivo Museo Cementerio San Pedro. 
Cada una de estas actividades vincula momentos de la memoria, que pasan de la memoria individual a un plano de ella inscrita a un territorio y dentro de un grupo social que permite el diálogo entre generaciones en la transmisión de un saber y de un recuerdo. Todas estas actividades le dan vida al cementerio, como un lugar con una carga simbólica tan fuerte y que sigue prestando sus servicios mortuorios, pero que está lleno de vida, al cual las personas que lo frecuentan le han perdido el temor, se ha resignificado como espacio de muerte, se movilizan las memorias y el espacio se convierte en el receptor de ellas.

\section{Análisis}

El análisis de estos casos parte de un elemento común a los tres lugares y es que hoy día su funcionalidad es otra respecto a la original y se fueron transformando durante los últimos años, además que comparten una intencionalidad pedagógica en sus actividades.

Las diferencias que quiero resaltar hacen referencia ya no al espacio físico y a sus transformaciones, sino al objetivo que la organización allí instalada procura, partiendo de esto resalto que:

- Su funcionalidad como lugar durante los últimos 15 años se ha transformado en razón del vínculo que se ha generado entre la organización con la comunidad a través de las actividades que realizan.

- Los relatos que conservan y/o construyen son diferentes en la medida en que el primer caso (ex Centro Clandestino de Detención Villa Grimaldi) está fundamentado en un relato de la memoria nacional que responde a un periodo específico del pasado reciente de Chile, mientras en los dos casos siguientes el relato es de carácter local y sus acciones aparecen como una forma de resistencia al conflicto.

- Las personas que hacen parte de estas experiencias pueden distinguirse en categorías diferentes, veamos: El primer caso está inscrito sobre la dialéctica víctima/victimario y el testimonio de los sobrevivientes es la base de la construcción del relato; en el caso de la Corporación Cultural en la Comuna 2 la experiencia de ese momento no está registrada a través de testimonios orales que aparezcan de manera espontánea, lo que se entrevé es una marca sobre las prácticas entre los habitantes que se mantienen en el tiempo. 
Para el último caso, la población son familiares que han perdido a un ser querido y ésta categoría se encuentra por fuera de ideas de víctimas inocentes, sicarios, narcotraficantes, es decir, el cementerio neutraliza las diferencias.

El caso de Villa Grimaldi opera aquí como herramienta metodológica, pues según la literatura abordada sería indiscutible que es un lugar de memoria, mientras que los demás lugares dadas sus actividades y el relato en el cual se inscriben no registran una memoria traumática inmediata, más si me arriesgo a afirmar que hacen parte de la memoria cultural de las zonas geográficas donde se encuentran ubicados y que a su vez aportan desde sus acciones a la recuperación, debate y disputa de la memoria política de la ciudad.

Considero así que bajo las características que ofrece Eugenia Allier [2008] son lugares de memoria porque:

-Aguardan un conflicto entre memorias

-Permiten la construcción de un relato de la memoria colectiva ya que su presencia e impacto en la comunidad refuerza elementos de la memoria individual.

-En esta medida otorga características identitarias locales vinculadas a un territorio y a un destino común.

Es decir, los casos de la ciudad de Medellín conservan en sí mismos la historia local de la ciudad, pero a su vez están cargados de miles de historias personales de los habitantes y se ha pensado como espacios para la cultura y la vida, como lugares de y para la memoria. Generan narrativas alternativas acerca del pasado a enfrentar, del sentido del recuerdo y de las respuestas que se dan a la violencia.

Cumplen con la descripción que hará Allier de los lugares de memoria -parafraseando a Nora- como lugares mixtos, híbridos y mutantes, íntimamente cargados de vida y de muerte, de tiempo y de eternidad. [2008]

\section{Conclusiones}

Después del análisis es posible pensar que la particularidad de los casos de Medellín radica principalmente en que no se dedican a reconstruir la memoria traumática de la ciudad -siendo el foco más importante de ella-, sino que el objetivo de sus acciones está dirigido hacia la recuperación de la memoria de la comunidad asociada a conocer sus procesos de poblamiento, sus modos de vida, en la búsqueda de la comprensión del sentido de la identidad, de las múltiples representaciones que se tienen sobre el territorio y de los sueños de futuro. 
Ambos espacios representan casi que de manera paralela la relación vida/muerte de una manera especial y su trabajo con la comunidad les ha permitido generar y proyectar sentidos de pertenencia y lazos de solidaridad con ellos. Los proyectos que realizan y que están enfocados a la recuperación de la memoria, hacen parte de sus líneas de trabajo y los ya ejecutados demuestran un sentido amplio de la noción de memoria y un especial cuidado y éxito de las metodologías implementadas, a pesar de no contar con amplios acercamientos teóricos al tema.

Hago énfasis en la idea de prácticas performativas como las define Allier, donde "el recuerdo no se materializa mediante la consagración de memoriales o la construcción de museos, sino que se realiza en las prácticas mismas de los actores sociales. Estas prácticas suponen modos alternativos de apropiación física y/o simbólica del espacio público y a menudo implican una renovación de los lenguajes estéticos y políticos. Allí la memoria es menos un relato apoyado en soportes diversos que un compromiso del cuerpo y un modo alerta de la conciencia; no un contenido a ser transmitido sino un acontecimiento colectivo. Son prácticas que no evocan sino que realizan, o son, ellas mismas la memoria. Como se sostienen en la participación colectiva, existen sólo en tanto existen individuos que las portan”. [2008]

Estas experiencias reivindican el rol y la importancia de ampliar el espectro de la historia reciente en lo que se refiere a los trabajos de la memoria, valorar aportes de trabajo sobre la misma que no se reducen a los de las memorias traumáticas de la ciudad, -discurso que comienza a tomar mucha fuerza y legitimidad y a su vez amenaza con convertirse en un discurso imperante-, donde lo que esté por fuera de la dialéctica víctima/victimario no tiene lugar y difícilmente es reconocida como memoria. En palabras de E. Schindel, este tipo de experiencias vinculadas al arte y a la memoria, permiten seguir plasmando y movilizando la historia que sigue construyéndose, es una memoria alerta y constante que se construye desde una experiencia sensible y cotidiana con el recuerdo. [2002:28].

Por último, el interés sobre estos procesos radica principalmente en que su proyección convierten a ambos casos estudiados y a las personas que se integran en los procesos en agentes de la memoria, y retomando la idea anteriormente expuesta llama la atención precisamente en que no se dedican a reconstruir la memoria traumática de la ciudad, sino que su deseo principal está en recuperar la memoria de la comunidad asociada a conocer sus procesos de poblamiento, sus modos de vida, en la búsqueda de la comprensión del sentido, de la identidad, de las múltiples representaciones que se 
tienen sobre el territorio y de los sueños de futuro. Asimismo, los proyectos están basados en diversos componentes que incluyen actividades académicas y artísticas, que a su vez procuran que el proceso en sí mismo sea formativo, tanto para las personas que participan de él como para quienes se convierten en espectadores.

Vuelvo a las preguntas iniciales: ¿Caben estos espacios dentro de la categoría lugar de memoria? ¿Existe una categoría que reúna mejor lo que el lugar es en sí mismo y lo que representa?

Después de abordar los casos y la bibliografía seleccionada para tal propósito, considero que los casos de la ciudad de Medellín presentados aquí -y que cómo estos hay muchos en las periferias de América Latina- merecen ser reconocidos como lugares de memoria desde una mirada ampliada de la noción, en la cual la idea de lugar esté más cercana a la reflexión de la geografía.

García Alvarez [2009:179:183] nos propone a la geografía de la memoria como una línea de investigación que se ha centrado en explorar las relaciones entre la memoria colectiva, los lugares y paisajes y las identidades nacionales, en la cual convergen aportaciones procedentes de ramas geográficas muy diversas (geografía cultural, la geografía histórica, la geografía política, la geografía urbana y al geografía feminista, sin olvidar la historia del pensamiento geográfico). En esta medida la dimensión geográfica de la memoria pensada como la relación entre la memoria y el espacio geográfico permitiría una lectura en clave de lo aquí propuesto: los lugares de memoria entendidos como son vividos por quienes los transitan, desde una dimensión urbana y cultural de la memoria y de entender el lugar como una comprensión afectiva del espacio. Entiendo la categoría lugar como aquello que "permite dar cuenta de atributos sensibles, dimensiones individuales y colectivas vinculadas a la emoción, tales como procesos de agenciamiento territorial y relaciones de vecindad, intimidad, cooperación y socialización". [AÓN, FREDIANI.2010:2]

"Las aportaciones geográficas han contribuido específicamente, entre otras cosas, a valorar la importancia de la escala en relación con los lugares y políticas de memoria; a analizar cómo ciertos espacios y lugares se articulan mediante estrategias narrativas dirigidas a exponer y representar el pasado de una determinada forma; y a cartografiar esas «topografías simbólicas»” [GARCÍA ÁLVAREZ. 2009:194]

Como parte de este ejercicio comparto la visión de la profesora mexicana Alicia Lindón, de la cual rescato la idea de construcción social del territorio, la cual considero condensa en buena medida las reflexiones aquí expuestas; afirma que "la construcción social del territorio es realizada por los habitantes locales con las concepciones del 
mundo, las ideas, las imágenes que tenían cuando llegaron al lugar, pero que también se siguen reconstruyendo a partir de la interacción de unos y otros. En ese proceso siempre en curso por las cuales las ideas, los sentidos se van entremezclando para construir un conocimiento compartido, una concepción del mundo que no es propiedad exclusiva de un individuo sino de un colectivo [...] Este conocimiento colectivo incluye formas de concebir la vida, el trabajo, la familia, el futuro o el pasado, formas de concebirse a sí mismo (identidad) y también incluye referentes territoriales, formas de identificar el territorio, de apropiarse de él, o expresiones de rechazo hacia el propio territorio habitado.” [2002:32]

\section{Referencias}

Aón, Laura C. Frediani, Julieta. La categoría de patrón territorial y el concepto de lugar aplicados al espacio residencial de la periferia del partido de La Plata. En: Párrafos Geográficos/ ISSN 1666-5783,9, N 1. 2010.

Allier Montaño, Eugenia. Lugar de memoria: ¿un concepto para el análisis de las luchas memoriales? En: Cuadernos del CLAEH. Vol.II, XXXI, n 96. 2008, p. 87-109

Díaz, Diego. El mapa de la memoria. En: Revista Puentes de la memoria, n 7.2002 , p. 34-39

Fabri, Silvia. Reflexionar sobre los lugares de memoria : Los emplazamientos de memoria como marcas territoriales. En: Geograficando, v 6 nº, 2010, p. 101-118

García Alvarez, Jacobo. Lugares, paisajes y políticas de la memoria: una lectura geográfica. En: Boletín de la A.G.E. $\mathrm{N}^{\circ}$ 51. 2009, p. 175-202

González, Horacio. Arte, grito y representación: entre la abstracción universalista y los nombres de la historia. En: BIRLE, Peter; CARNOVALE, Vera; GRYGLEWSKI, Elke y SCHINDEL, Estela (ed.), Memorias urbanas en diálogo: Berlín y Buenos Aires. Buenos Aires, Editorial Buenos Libros, cap. V. 2010, p. 229-239

Jelin, Elizabeth. Los trabajos de la memoria. Madrid: Siglo Veintiuno de España Editores / Siglo Veintiuno de Argentina Editores, 2002.

Lindón, Alicia. La construcción social del territorio y los modos de vida en la periferia metropolitana. En: Territorios (Bogotá) No 7, 2002, p. 27-41

Ruiz Tagle, Diana y Toledo, María Isabel. Del uso pedagógico de lugares de memoria: visita de estudiantes de educación media al parque por la Paz Villa Grimaldi (Santiago, Chile) En: Estudios Pedagógicos XXXV, N 1. 2009, p. 199-220 
Schindel, Estela. Cómo la historia marca el espacio urbano. Las ciudades y el olvido. En: Revista Puentes de la Memoria N 7. 2002, p. 26-32

Schindel, Estela. Lugares de Memoria en Buenos Aires. En: BIRLE, Peter; CARNOVALE, Vera; GRYGLEWSKI, Elke y SCHINDEL, Estela (ed.), Memorias urbanas en diálogo: Berlín y Buenos Aires. Buenos Aires, Editorial Buenos Libros. 2010, cap. III, p. 85-101

Recebido para publicação em outubro de 2012 Aprovado para publicação em novembro de 2012 